\title{
Avaliação de indutores de resistência em algodoeiro a murcha de fusário: atividade enzimática e índice de infecção
}

\author{
Erick F. Couto ${ }^{1}$, Rildo S.B. Coelho ${ }^{2}$, Nelson D. Suassuna ${ }^{3}$ \& Sônia M.A. Oliveira ${ }^{1}$ \\ ${ }^{1}$ Departamento de Agronomia, Área de Fitossanidade, Universidade Federal Rural de Pernambuco, 52171-900, Recife, PE, \\ Brasil; ${ }^{2}$ Empresa Pernambucana de Pesquisa Agropecuária - IPA, 50761-000, Recife, PE, Brasil; ${ }^{3}$ EMBRAPA Algodão, \\ 58107-720, Campina Grande, PB, Brasil
}

Autor para correspondência: Sônia M.A. Oliveira, e-mail: smao@ufrpe.br

\begin{abstract}
RESUMO
Os indutores de resistência acibenzolar-S-metil, metil jasmonato e fosfato de potássio $\left(\mathrm{K}_{2} \mathrm{HPO}_{4}\right)$, nas concentrações de $0,2 \mathrm{~g} / \mathrm{L}$, $0,1 \mathrm{~mL} / \mathrm{L}$ e $0,1 \mathrm{M}$, respectivamente, foram testados em plântulas de algodoeiro (cv. BRS Cedro), para o controle de Fusarium oxysporum f. sp. vasinfectum. Foram realizadas uma e duas aplicações com todos os indutores em plântulas com e sem inoculação do fitopatógeno. Constatou-se que o menor índice de infecção foi obtido com o uso do metil jasmonato aplicado duas vezes. Amostras de folhas e caule foram avaliadas quantitativamente para as enzimas $\beta$-1,3-glucanase, peroxidase e quitinase. As plantas testemunhas sem inoculação apresentaram as maiores atividades das enzimas peroxidase e $\beta$-1,3-glucanase no caule. Nas folhas das plantas que receberam os tratamentos com metil jasmonato (uma aplicação com inoculação), a atividade das enzimas peroxidase e quitinase foram as maiores. Nas amostras de caule não houve atividade detectada da enzima quitinase.
\end{abstract}

Palavras-chave: Fusarium oxysporum f.sp. vasinfectum, PR proteínas, eliciadores.

\begin{abstract}
Evaluation of induced resistance to Fusarium wilt in cotton: elicited enzymatic activity and disease index

Acibenzolar-S-methyl, methyl jasmonate and $\mathrm{K}_{2} \mathrm{HPO}_{4}$ (potassium phosphate), at $0.2 \mathrm{~g} / \mathrm{L}, 0.1 \mathrm{~mL} / \mathrm{L}$ and $0.1 \mathrm{M}$ respectively, were tested in cotton seedlings cv. 'BRS Cedro' (susceptibility standard) for controlling Fusarium oxysporum f. sp. vasinfectum. One and two applications on the seedlings were tested with and without the pathogen. The treatment with methyl jasmonate (two applications) showed the lowest disease index. Samples of leaves and stem were quantitatively evaluated for $\beta$-1,3-glucanase, peroxidase and chitinase. The controls without pathogen inoculation showed higher activity of the enzymes peroxidase and $\beta$-1,3-glucanase in the stem. In the leaves, the activity of peroxidase and chitinase was highest for methyl jasmonate (one application with inoculation) treatment. There was no chitinase activity observed in the stem.
\end{abstract}

Keywords: Fusarium oxysporum f.sp. vasinfectum, elicitors, PR proteins.

O algodoeiro (Gossypium spp.) é atualmente uma das culturas anuais mais importantes para o Brasil, tanto como "commoditie" quanto pelo seu valor social. Dentre as doenças que acometem os algodoais, a murcha vascular causada por Fusarium oxysporum f.sp. vasinfectum W.C. Snyder \& H.N. Hansen destaca-se como uma das mais importantes. O manejo da doença é realizado principalmente pela exclusão, utilizando-se sementes livres do fitopatógeno. Outras táticas importantes são rotação de culturas e o uso de cultivares resistentes. Em relação ao desenvolvimento de cultivares resistentes, muitas vezes o processo é demorado e características indesejáveis podem ser incorporadas junto com caracteres desejados (Quirino \& Bent, 2003). As plantas, ao longo da co-evolução com os microrganismos que incitam enfermidades, desenvolveram mecanismos de defesas, os mais variados possíveis. Tais mecanismos podem existir tanto antes quanto após o contato com o fitopatógeno. Durante esta interação patógeno-hospedeiro, ocorre uma série de eventos bioquímicos que levam a ativação de defesas por parte da planta, resultando na produção de compostos que podem ser tóxicos ao fitopatógeno ou apenas restringir o seu desenvolvimento. A resposta da planta pode ser verificada por mudanças bioquímicas nas células, ocorrendo o acúmulo de proteínas relacionadas à patogênese (PR proteínas) tais como glucanases, peroxidases e quitinases; produção de fitoalexinas e modificações na parede celular como deposição de caloses e lignificação (Wróbel-Kwiatkowska et al., 2004).

Uma das estratégias de controle de doenças do algodoeiro é a utilização da indução de resistência, a qual é definida como um fenômeno onde a resistência a um agente patogênico é sistemicamente induzida por uma infecção localizada ou tratamento com produtos microbianos e compostos orgânicos ou inorgânicos de natureza estrutural não relacionada (Kúc, 2001). Em cultivares de tomateiro (Lycopersicon esculentum) suscetíveis a $F$. oxysporum 
f.sp. radicis-lycopersici, $\beta$-1,3-glucanase é acumulada em pontos próximos as células fúngicas, porém, em cultivares resistentes, tecidos não invadidos também possuem acúmulo desta enzima (Benhamou et al. 1989). O objetivo do presente trabalho foi avaliar os produtos acibenzolar-S-metil, metil jasmonato e fosfato de potássio na indução de resistência da cv. 'BRS Cedro' de algodoeiro a $F$. oxysporum f. sp. vasinfectum, mediante a determinação da atividade das enzimas $\beta$-1,3-glucanase, peroxidase e quitinase em amostras de folhas e caule bem como determinar o índice de infecção da murcha do algodoeiro em plântulas inoculadas com o fitopatógeno.

Sementes da cultivar 'BRS Cedro' de algodoeiro, padrão de suscetibilidade $F$.oxysporum f.sp.vasinfectum, foram semeadas em copo plástico (volume de $200 \mathrm{~mL}$ ), contendo solo previamente esterilizado. Quinze dias após o plantio foi realizada a primeira aplicação dos indutores através da pulverização com o auxílio de atomizador até o ponto de escorrimento. Aos seis dias após a primeira aplicação dos indutores foi realizada a inoculação de $F$. oxysporum f. sp. vasinfectum, através do método de imersão de raízes (Pastor-Corrales \& Abawi, 1987), por cinco minutos, utilizando uma suspensão de $10^{6}$ conídios/ $\mathrm{mL}$ transferindo-se posteriormente as plântulas para vaso plástico (volume de $500 \mathrm{~mL}$ ) contendo solo esterilizado. Após cinco dias da inoculação, realizou-se uma segunda pulverização. Para todos os indutores, plântulas foram pulverizadas uma e duas vezes, com e sem inoculação do fungo. Foram incluídas duas testemunhas, uma com inoculação e outra sem inoculação do fitopatógeno, ambas sem aplicação de indutor. A unidade experimental foi composta de um vaso com três plantas e 10 repetições. $O$ fungo $F$. oxysporum $\mathrm{f}$. sp. vasinfectum foi cedido pelo laboratório de fitopatologia da Embrapa Algodão, Campina Grande, PB. Os indutores utilizados foram acibenzolar-S-metil (ASM), metil jasmonato (MeJ) e $\mathrm{K}_{2} \mathrm{HPO}_{4}$ (fosfato de potássio), nas concentrações de 0,2 $\mathrm{g} / \mathrm{L}, 0,1 \mathrm{~mL} / \mathrm{L}$ e $0,1 \mathrm{M}$, respectivamente.

A severidade da doença foi avaliada 45 dias após a inoculação. Para tanto foram atribuídas notas de 0 a 4 (Huertas-González et al., 1999), sendo 0- plântulas sem sintomas; 1- início do aparecimento de sintomas de murcha nas folhas; 2- plântulas com duas folhas com sintomas de murcha; 3 - todas as folhas murchas; e 4- plântula morta. A partir das notas foi obtido o índice de infecção (I), expresso como $\mathrm{I}=\operatorname{sen}^{2} \omega$, para cada distribuição de freqüência obtida na parcela (Amaral, 1969). Foi realizada a transformação angular $\omega=\operatorname{arcsen} \sqrt{I}$ para ser possível realizar a análise de variância (Czermainski, 1999). A variável $\omega$ foi calculada para se converter notas em escala de intervalo. O delineamento experimental foi o inteiramente casualizado e os valores de cada repetição foram submetidos a análise de variância e comparadas pelo teste de Tukey a $5 \%$ de probabilidade.

Amostras de folhas e caule foram coletadas dois dias após a segunda aplicação, sendo estas congeladas imediatamente com o auxílio de nitrogênio líquido e armazenadas em freezer $-24^{\circ} \mathrm{C}$. O preparo do extrato bruto enzimático foi realizado imediatamente após a coleta das amostras no qual $1,5 \mathrm{~g}$ de folhas ou de caule, correspondentes a cada tratamento, foram maceradas com o auxílio de nitrogênio líquido adicionando-se $0,3 \mathrm{~g}$ de polivinilpirrolidona (PVP) e 4,0 mL de tampão acetato de sódio $(0,1 \mathrm{M}$ e pH 5,0), contendo $1,0 \mathrm{mM}$ de EDTA. As amostras dos extratos foram congeladas em freezer $20^{\circ} \mathrm{C}$ durante 12 horas e, após este período, centrifugadas a $14000 \mathrm{rpm}$ por 25 minutos $\left(4^{\circ} \mathrm{C}\right)$, transferindo-se o sobrenadante para novos tubos eppendorfs ao final, armazenando-os a $-80^{\circ} \mathrm{C}$. O extrato bruto de cada um dos tratamentos foi utilizado para a determinação de todas as enzimas. Para todas as enzimas o delineamento foi o inteiramente casualizado sendo os dados submetidos a análise de variância e as médias comparadas através do método de Tukey ao nível de $5 \%$ de probabilidade.

A atividade da $\beta$-1,3-glucanase (EC 3.2.1.6) foi realizada segundo Giri et al. (1998). Para um tanto, em um tubo de ensaio rosqueável, foram pipetados $5,0 \mu \mathrm{L}$ do extrato enzimático, sendo adicionados $5,0 \mu \mathrm{L}$ do tampão acetato de sódio $(0,1 \mathrm{M} \mathrm{e} \mathrm{pH} \mathrm{5,0)} \mathrm{e} \mathrm{5,0} \mu \mathrm{L}$ de laminarina $(4,0 \mathrm{mg} / \mathrm{mL})$. Os ensaios em branco foram realizados adicionando-se $5,0 \mu \mathrm{L}$ de água destilada no lugar da laminarina, em número de três repetições analíticas, para cada repetição dos tratamentos. A mistura de reação foi incubada a $40^{\circ} \mathrm{C}$ por uma hora. A determinação da atividade da $\beta$-1,3-glucanase foi realizada através da quantificação colorimétrica da glicose liberada a partir da hidrólise da laminarina. Esta quantificação foi realizada mediante o uso da hidrazida do ácido $\rho$-hidroxibenzóico (HAPHB) (Lever, 1972). Para tanto, acrescentou-se 4,0 $\mathrm{mL}$ de uma solução de HAPHB $(0,5 \mathrm{~g}$ HAPHB dissolvido em $10,0 \mathrm{~mL}$ de HCL $0,5 \mathrm{M}$, adicionando-se posteriormente $40,0 \mathrm{~mL}$ de $\mathrm{NaOH}$ 0,5 M) à mistura de reação. A solução contendo a mistura de reação juntamente com o HAPHB foi imersa em banho-maria a aproximadamente 100 ${ }^{\circ} \mathrm{C}$. A solução permaneceu no banho-maria durante cinco minutos, sendo, posteriormente, resfriada em banho de gelo. O valor da absorbância das amostras foi determinado em espectrofotômetro no comprimento de onda de $610 \mathrm{~nm}$. Os resultados foram confrontados com curva padrão composta por concentrações conhecidas de glicose $(\mathrm{mg} / \mathrm{L})$. Os resultados foram expressos em $\mathrm{mg}$ de glicose/mg de proteína/por minuto.

A atividade da peroxidase (EC 1.11.1.7) (Dann \& Deverall, 2000) foi realizada diretamente em uma cubeta de espectrofotômetro, sendo as alíquotas acrescentadas seguindo-se esta ordem: $25 \mu \mathrm{L}$ de guaiacol $(0,02 \mathrm{M}) ; 1,0$ $\mathrm{mL}$ do tampão acetato de sódio $(0,1 \mathrm{M}$ e pH 5,0); 250 $\mu \mathrm{L}$ de peróxido de hidrogênio $(0,38 \mathrm{M})$. A mistura foi agitada e serviu como ponto zero no espectrofotômetro. Após a realização deste procedimento, $25 \mu \mathrm{L}$ do extrato enzimático foram adicionados a mistura e rapidamente realizou-se uma leve agitação, seguindo-se da colocação 
do tubo no espectrofotômetro. A primeira leitura após a adição do extrato e a leitura após dois minutos de reação foram registradas. A determinação da atividade da peroxidase foi realizada, portanto, medindo-se, a variação da absorbância após dois minutos de reação, no comprimento de onda de $470 \mathrm{~nm}$, do tetraguaiacol formado pela ação da reação enzimática. Para cada repetição dos tratamentos, realizaram-se três repetições analíticas. Uma unidade de atividade $(\mathrm{UA} / \mathrm{mL})$ foi definida como a quantidade de enzima que causou o aumento de 0,001 unidade de absorbância por $\mathrm{mL}$ da mistura por minuto de reação, nas condições supracitadas. Os resultados foram expressos em atividade específica (UA/mg proteína/ minuto de reação).

A atividade da quitinase (EC 3.2.1.14) (Dann \& Deverall, 2000) foi realizada mediante a adição, em um tubo de ensaio rosqueável de: $200 \mu \mathrm{L}$ do extrato protéico; $600 \mu \mathrm{L}$ do tampão acetato de sódio $(0,1 \mathrm{M} / \mathrm{pH} 5.0)$; e $200 \mu \mathrm{L}$ de CM-Chitin-RBV $(2,0 \mathrm{mg} / \mathrm{mL})$, fornecido pela Loewe Biochemica $\mathrm{GmbH}$. A mistura foi incubada por 20 minutos a $40^{\circ} \mathrm{C}$, sendo paralisada com $200 \mu \mathrm{L}$ de $\mathrm{HCL}$ $1,0 \mathrm{M}$. Amostras em branco foram realizadas mediante o preparo de igual mistura de cada repetição dos tratamentos, com a exceção do período de incubação a $40^{\circ} \mathrm{C}$. As amostras foram centrifugadas por cinco minutos a $5000 \mathrm{~g}\left(4^{\circ} \mathrm{C}\right)$, coletando-se o sobrenadante. As leituras espectrofotométricas foram realizadas no comprimento de onda de $550 \mathrm{~nm}$. Três repetições analíticas de cada repetição dos tratamentos foram realizadas. Os resultados foram expressos em unidade enzimática (UA)/mg proteína/minuto de incubação, onde 1 UA equivale a leitura de absorbância a $550 \mathrm{~nm} / \mathrm{mL}$. O teor de proteína solúvel foi determinado de acordo com o método colorimétrico descrito por Bradford (1976) utilizando-se albumina sérica bovina (BSA) como padrão.

As plantas testemunhas não inoculadas foram aquelas que demonstraram os maiores índices para as enzimas peroxidase e $\beta$-1,3-glucanase em amostras de caule (Tabela 1), diferindo significativamente das demais. Este resultado está em discordância daqueles reportados por Soares et al. (2004) que obtiveram maior atividade da peroxidase em tratamentos pulverizados com ASM comparado com os não pulverizados. Por outro lado, Pelt-Heerschap \& Bakker (1999) encontraram resultados semelhantes aos obtidos neste experimento para a enzima $\beta$-1,3-glucanase, ou seja, ocorreram diferenças entre os tratamentos e a testemunha. Para os demais tratamentos ocorreram diferenças para a atividade da peroxidase enquanto que para a atividade da $\beta$-1,3-glucanase os tratamentos foram agrupados em um único bloco.

No tratamento ASM (duas aplicações) foi constatado um aumento da atividade das enzimas peroxidase e $\beta$-1,3-glucanase por ocasião da inoculação enquanto que para o tratamento com $\mathrm{MeJ}$ (uma ou duas aplicações) as plantas não inoculadas apresentaram maiores quantidades destas enzimas. Ao contrário dos dados aqui apresentados, Liljeroth et al. (2001) relataram que a diminuição da produção das PR proteínas durante a patogênese pode estar relacionada a atuação do fitopatógeno o qual promove uma inativação destas enzimas.

Quando comparados os tratamentos inoculados e não inoculados, percebe-se resultado inverso ao que ocorreu com as enzimas peroxidase e $\beta$-1,3-glucanase, ou seja, a inoculação com o fitopatógeno interferiu na atividade da enzima, ocorrendo em alguns tratamentos um aumento do nível enzimático e diminuição em outros. Para todos os indutores, a atividade da enzima $\beta$-1,3-glucanase nas folhas foi, de um modo geral, oito vezes inferior aos níveis no caule com exceção apenas para o indutor $\mathrm{K}_{2} \mathrm{HPO}_{4}$ (duas aplicações com inoculação) enquanto que os níveis da peroxidase foram semelhantes nas amostras de folha e caule (Tabela 1). Em desacordo com os dados aqui apresentados, Soares et al. (2004) encontraram uma maior atividade da peroxidase em amostras de folha do que em amostras de caule de feijoeiro, podendo este fato estar relacionado a maior eficiência do ASM na indução de resistência à fitopatógenos que colonizam a parte aérea.

Apesar do tratamento $\mathrm{K}_{2} \mathrm{HPO}_{4}$ (duas aplicações com inoculação) ter apresentado o maior nível de $\beta$ 1,3-glucanase, este não diferiu significativamente dos tratamentos $\mathrm{K}_{2} \mathrm{HPO}_{4}$ (uma aplicação, sem inoculação), ASM (duas aplicações, sem inoculação), ASM (duas aplicações, com inoculação) e testemunha (sem inoculação), mostrando que a inoculação com o fitopatógeno não teve influência sobre a expressão desta enzima. O tratamento MeJ (uma aplicação, com inoculação) apresentou maiores atividades das enzimas peroxidase e quitinase, porém, para a enzima quitinase não houve diferença significativa com o tratamento MeJ (uma aplicação, sem inoculação). Quando por ocasião da segunda aplicação, de modo geral houve um decréscimo na atividade da peroxidase tanto nas plantas inoculadas quanto nas não inoculadas, isto leva a crer que uma superativação das defesas mediadas pela rota do jasmonato tem como característica uma auto inibição da atividade da peroxidase. Estes mesmos resultados podem ser observados para os tratamentos com MeJ em relação a enzima quitinase. Pelt-Heerschap \& Bakker (1999) citam que a expressão da peroxidase está mais relacionada com injúrias físicas do que com a atividade patogênica.

A atividade da quitinase, com exceção do tratamento MeJ (uma aplicação sem inoculação), não diferiu significativamente entre os demais tratamentos. Pelt-Heerschap \& Baker (1999) encontraram atividade similar da enzima quitinase nos tratamentos com a testemunha sugerindo que a atividade da quitinase é constitutiva. Os dados obtidos no presente trabalho sugerem o contrário, ou seja, na interação algodoeiro $\mathrm{x}$ $F$. oxysporum f.sp. vasinfectum a atividade da enzima quitinase é favorecida pelos tratamentos com MeJ. No 
TABELA 1 - Índice de infecção e atividade das enzimas peroxidase e $\beta$-1,3-glucanase em amostras de caule e peroxidase, $\beta$-1,3-glucanase e quitinase em amostras de folhas de plântulas de algodoeiro da cultivar BRS Cedro após uma ou duas aplicações de acibenzolar-S-metil, metil jasmonato e $\mathrm{K}_{2} \mathrm{HPO}_{4}$ inoculadas e não inoculadas com Fusarium oxysporum f. sp. vasinfectum (Fov)

\begin{tabular}{|c|c|c|c|c|c|c|c|}
\hline \multirow[t]{2}{*}{ Tratamentos } & \multirow{2}{*}{$\begin{array}{c}\mathbf{N}^{0} \text { de } \\
\text { Aplicações }\end{array}$} & \multicolumn{2}{|c|}{ Caule } & \multicolumn{3}{|c|}{ Folha } & \multirow{2}{*}{$\begin{array}{l}\text { Índice } \\
\text { de } \\
\text { Infecção }\end{array}$} \\
\hline & & Peroxidase* & $\begin{array}{c}\beta-1,3- \\
\text { Glucanase* }\end{array}$ & Peroxidase* & $\begin{array}{c}\beta-1,3- \\
\text { Glucanase* }\end{array}$ & Quitinase* & \\
\hline Testemunha + Fov & 0 & $4241,6 \mathrm{~cd}$ & $12,1 b$ & $4667,0 \mathrm{~d}$ & $2,74 \mathrm{bcd}$ & $0,26 b$ & $68,05 \mathrm{a}$ \\
\hline Testemunha & 0 & $31944,5 a$ & $63,0 \mathrm{a}$ & $7079,2 d$ & $4,91 \mathrm{abc}$ & $0,28 b$ & - \\
\hline Metil Jasmonato + Fov & 1 & $2775, \mathrm{~d}$ & $2,8 b$ & $37676,2 \mathrm{a}$ & $1,33 \mathrm{~cd}$ & $2,18 \mathrm{a}$ & $63,49 b$ \\
\hline Metil Jasmonato & 1 & $3058,4 d$ & $11,1 \mathrm{~b}$ & $15791,5 \mathrm{bc}$ & $2,64 \mathrm{~cd}$ & $1,06 \mathrm{ab}$ & - \\
\hline Metil Jasmonato + Fov & 2 & $3328,6 \mathrm{~d}$ & $5,7 \mathrm{~b}$ & $19369,7 b$ & $2,77 \mathrm{bcd}$ & $0,71 b$ & $45,00 \mathrm{~d}$ \\
\hline Metil Jasmonato & 2 & $8213,4 \mathrm{c}$ & $16,6 b$ & $7629,1 d$ & $0,42 \mathrm{~d}$ & $0,31 b$ & - \\
\hline Acibenzolar-S-metil + Fov & 1 & $3591,2 d$ & $2,3 b$ & $3044,2 d$ & $2,16 \mathrm{~cd}$ & $0,33 b$ & $49,61 \mathrm{c}$ \\
\hline Acibenzolar-S-metil & 1 & $1262,9 \mathrm{~d}$ & $2,5 b$ & $20,27,7 \mathrm{~d}$ & $0,74 \mathrm{~d}$ & $0,16 b$ & - \\
\hline Acibenzolar-S-metil + Fov & 2 & $12707,4 \mathrm{~b}$ & $20,7 b$ & $4366,3 d$ & $4,18 \mathrm{abcd}$ & $0,27 b$ & $61,89 b$ \\
\hline Acibenzolar-S-metil & 2 & $3372,2 \mathrm{~d}$ & $6,0 \mathrm{~b}$ & $4372,2 d$ & $6,75 \mathrm{ab}$ & $0,49 b$ & - \\
\hline $\mathrm{K}_{2} \mathrm{HPO}_{4}+$ Fov & 1 & $2220,5 \mathrm{~d}$ & $2,3 b$ & $69,2 a$ & $1,25 \mathrm{~cd}$ & $0,13 b$ & $60,78 b$ \\
\hline $\mathrm{K}_{2} \mathrm{HPO}_{4}$ & 1 & $1273,0 \mathrm{~d}$ & $1,1 \mathrm{~b}$ & $6723,0 \mathrm{~d}$ & $3,86 \mathrm{abcd}$ & $0,39 b$ & - \\
\hline $\mathrm{K}_{2} \mathrm{HPO}_{4}+\mathrm{Fov}$ & 2 & $1983,5 \mathrm{~d}$ & $3,7 \mathrm{~d}$ & $8931,8 \mathrm{~cd}$ & $7,72 \mathrm{a}$ & $0,31 b$ & $50,89 \mathrm{c}$ \\
\hline $\mathrm{K}_{2} \mathrm{HPO}_{4}$ & 2 & $2565,1 d$ & $2,0 \mathrm{~b}$ & $6014,7 \mathrm{~d}$ & $0,56 \mathrm{~d}$ & $0,19 b$ & - \\
\hline
\end{tabular}

${ }^{*}$ Atividade de $\beta$-1,3-glucanase expressa em $\mathrm{mg}$ de glicose/mg de proteína/por minuto e da peroxidase e quitinase em UA/mg proteína/minuto de reação. Médias seguidas de mesma letra nas colunas não diferem estatisticamente pelo teste de tukey a 5\% de probabilidade.

tratamento testemunha com inoculação obteve-se o índice de infecção $(68,05)$ diferindo significativamente dos demais. Os tratamentos MeJ (uma aplicação), ASM (duas aplicações) e $\mathrm{K}_{2} \mathrm{HPO}_{4}$ (uma aplicação) não diferiram significativamente, apresentando os índices de 63,49, 61,89 e 60,78 , respectivamente. Os tratamentos $\mathrm{K}_{2} \mathrm{HPO}_{4}$ (duas aplicações) e ASM (uma aplicação) foram agrupados juntos tendo seus índices de infecção de 50,89 e 49,61, respectivamente. Em relação à atividade das enzimas avaliadas no presente trabalho com o índice de infecção na cultivar 'BRS Cedro', verifica-se que a atividade da peroxidase na folha pode estar relacionada com a redução do índice de infecção

O tratamento ASM (duas aplicações) apresentou as maiores atividades das enzimas peroxidase e $\beta-1,3-$ glucanase no caule, porém, este fato não foi capaz de reduzir a severidade da murcha. Nas folhas, os tratamentos com ASM, tanto uma quanto duas aplicações, apresentaram valores semelhantes para todas as enzimas, porém, com apenas uma aplicação o índice de infecção foi inferior (Tabela 1). A atividade da peroxidase a partir da indução de resistência advém de uma seqüência de ativação de sinais que culminam com a biossíntese da lignina, a qual serve como barreira ao fitopatógeno. A atividade da peroxidase em folhas induzidas com MeJ (uma aplicação) e ASM (duas aplicações) no caule foram superiores aos demais tratamentos, tendo o índice de infecção, em ambos os casos $(63,49$ e 61,89), não diferido significativamente. Diante dos resultados obtidos, houve uma variação na atividade enzimática entre os tratamentos inoculados e não inoculados e entre amostras de folhas e caule, demonstrando que as enzimas são expressas diferentemente nos vários tecidos das plântulas do algodoeiro. Fica evidente que o tratamento MeJ (duas aplicações com inoculação) mostrou-se o mais eficaz na redução do índice de doença sendo portanto o mais promissor no controle da murcha do algodoeiro.

\section{REFERÊNCIAS BIBLIOGRÁFICAS}

Amaral E (1969) Novo índice de intensidade de infecção. Pesquisa Agropecuária Brasileira 4:1-2.

Benhamou N, Grenier J, Asselin A, Legrand M (1989) Immunogold localization of $\beta$-1,3-glucanases in two plants infected by vascular wilt fungi. The Plant Cell 1:1209-1221.

Bradford M (1976) A rapid and sensitive method for the quantification of microgram quantities of protein utilizing the principle of protein-dye binding. Analytical Biochemistry 72:248254.

Czermainski ABC (1999) Generalização de um índice de intensidade de infecção em experimentos de avaliação de doenças em plantas. Pesquisa Agropecuária Brasileira 34:1545-1555.

Dann EK, Deverall BJ (2000) Activation of systemic disease resistance in pea by an avirulent bacterium or a benzothiadiazole, but not by a fungal leaf spot pathogen. Plant Pathology 49:324332.

Giri AP, Harsulkar AM, Patankar AG, Gupta VS, Sainani MN, Deshpande VV, Ranjekar PK (1998) Association of induction of protease and chitinase in chickpea roots with resistance to Fusarium oxysporum f. sp. ciceri. Plant Pathology 47: 693-699. 
Huertas-González MD, Ruiz-Roldán MC, Di Pietro A, Roncero MIG (1999) Cross protection provides evidence for race-specific avirulence factors in Fusarium oxysporum. Physiological and Molecular Plant Pathology 54:63-72.

Kúc J (2001) Concepts and direction of induced systemic resistance in plants and its application. European Journal of Plant Pathology 107:7-12.

Lever M (1972) A new reaction for colorimetric determination of carbohydrates. Analytical Biochemistry 47:273-279.

Liljeroth E, Santen K, Bryngelsson T (2001) PR protein accumulation in seminal roots of Barley and wheat in response to fungal infection - the importance of cortex senescence. Journal of Phytopathology 149:447-456.

Pastor-Corrales MA, Abawi GS (1987) Reactions of selected bean germplasm to infection by Fusarium oxysporum f. sp. phaseoli. Plant Disease 71:990-993.
Pelt-Heerschap HV, Bakker OS (1999) Analysis of defence-related proteins in stem tissue of carnation inoculated with a virulent and avirulent race of Fusarium oxysporum f. sp. dianthi. European Journal of Plant Pathology 105:681-691.

Quirino BF, Bent AF (2003) Deciphering host resistance and pathogen virulence: the Arabidopsis/Pseudomonas interaction as a model. Molecular Plant Pathology 4:517-530.

Soares RM, Maringoni AC, Lima GPP (2004) Ineficiência de acibenzolar-S-methyl na indução de resistência de feijoeiro comum à murcha-de-Curtobacterium. Fitopatologia Brasileira 29:373-377.

Wróbel-Kwiatkowska M, Lorenc-Kukula K, Starzycki M, Oszmianski J, Kepczynska E, Szopa J (2004) Expression of $\beta-1,3-$ glucanase in flax causes increased resistance to fungi. Physiological and Molecular Plant Pathology 65:245-256.

TPP 8032 - Recebido 21 Outubro 2008 - Aceito 21 Julho 2009
Editor de Seção: Mário Lúcio V. de Resende 